\title{
Plasma facing material by self-interstitial solid solution strengthening - problem, proposition, and a solution
}

\author{
Muhammad Musaddique Ali Rafique \\ Eastern Engineering Solutions LLC, Detroit, MI 48202
}

\begin{abstract}
Bubble (point defect) - a precursor of fuzz or under dense nanostructure formation is crystal lattice defect. Suitable selection of crystal lattice which inhibit Frenkel pair generation and intrinsically promotes selfinterstitial solid solution strengthening contributes effectively towards making plasma facing material. For this, interstitial sites, their size, amount / fraction, positions, tendency of occupation and diffusion parameters (e.g. activation energies (Q), activation volumes) are determined. Fcc iron carbon alloys (austenitic stainless steels AISI / SAE 321, fcc structure, Pearson code cF4, space group Fm $\overline{3} m$ ) are proposed as suitable candidates. Along with their room temperature fcc structure having 12 interstitial positions ( 4 octahedral, 6 coordination sites and 8 tetrahedral, 4 coordination sites / unit cell) to allow insertion of self (iron) atoms, they have excellent corrosion resistance, thermal conductivity, and nonmagnetic properties. After their melting, casting, and machining to required dimensions and geometry, stabilizing heat treatment is applied to precipitate all carbon as TiC and prevent formation of $\mathrm{Cr}_{23} \mathrm{C}_{6}$ (sensitization). This resist heat and surface degradation and yield excellent architecture which not only inhibit Frankel pair generation but will also allow bulk assimilation or surface annihilation (loop punching) of this lattice point defect. A superior thermal, fluid, and structural design augment above.
\end{abstract}

Keywords: point defect, crystal lattice, interstitial, austenitic, stabilization 


\section{Introduction and background}

Harnessing terra watts of energy available during nuclear fusion is an avenue of great interest and potential benefit to overcome tomorrow's energy requirements of society. In general, following reactions occur during fusion [1]

$$
\begin{array}{ll}
\mathrm{D}+\mathrm{T} \longrightarrow & \alpha(3.52 \mathrm{MeV})+\mathrm{n}(14.06 \mathrm{MeV}) \\
\mathrm{D}+{ }^{3} \mathrm{He} \longrightarrow & \alpha(3.67 \mathrm{MeV})+\mathrm{H}(14.69 \mathrm{MeV}) \\
\mathrm{D}+\mathrm{D} \longrightarrow \mathrm{T}(1.01 \mathrm{MeV})+\mathrm{H}(3.03 \mathrm{MeV}) & \\
\mathrm{D}+\mathrm{D} \longrightarrow{ }^{3} \mathrm{He}(0.82 \mathrm{MeV})+\mathrm{n}(2.45 \mathrm{MeV}) \\
\mathrm{T}+\mathrm{T} \longrightarrow{ }^{4} \mathrm{He}(3.77 \mathrm{MeV})+2 \mathrm{n}(7.53 \mathrm{MeV})
\end{array}
$$

Of these, reactions 1 is most feasible. Its cross section $(\alpha)$ is around $70 \mathrm{KeV}$ but high $\mathrm{D}-\mathrm{T}$ reactivity is reached already at $20 \mathrm{KeV}$. Various methods based on design [2-39], manufacturing and control have been proposed to harness this energy. However, mostly they are limited by availability of suitable material directly facing and interacting plasma. Ideal material is required to possess superior physical (high melting point, high temperature stability, high thermal conductivity [40], high corrosion resistance (both at room and elevated temperature)), design [41, 42], mechanical (high strength, high hardness, high thermal shock resistance, high creep resistance, high thermo-cyclic creep, high cyclic plasticity [43], high thermal fatigue resistance, fracture resistance [44]), structural (excellent shear stress, shear strain, bending moment, torsion, dimensional stability at elevated temperatures [45]), manufacturing (easy formability (e.g. rolling, bending, cutting, cladding, weldability [46])) and nuclear (low sputtering yield, low tritium retention) properties.

To this end, various materials (such as W [47-50], addition of Rh in W [51], use of bcc Fe [52, 53], Ta [54], W-Ta [55], Ta/Fe [56], Pd [57], nanocrystalline Cu [58], SiOC/Crystalline Fe nanocomposite [59], W-K [60], reduced activation steel [61], ferritic [62], ferritic/martensitic steels [63], Be pebbles [64-67], Be and beryllides [68], graphite, carbon fiber composite [69]) and high Z atoms ( $\mathrm{Zr}$, No, Mo, Hf, Ta) [70] have been tested but none proved satisfactory [71-74]. All show rapid surface degradation exhibiting surface blisters [75-78] and formation of fuzz [51, 79-82] or under dense nanostructure [40] after bubble. These rapidly degrade their physical (e.g. ability to contain plasma by inverse or re-radiation due to excellent surface finish), mechanical and aforementioned properties. It is hypothesized that production of surface nanostructure (nanochannels) [83-86] will help escape of He [60, 87-91] inhibiting formation (nucleation and growth (crystallography) [90] or precipitation and coalescence (physical chemistry)) of bubble and restricts surface degradation. However, this is poorly understood and wrongfully approached. It has been approached by physical chemistry, surface engineering, chemical engineering, process engineering, nuclear engineering, and nuclear physics point of view but none made use of fundamental physical metallurgy principles.

\section{Bubble}

Bubble is described in many ways. Historically, it has been described in chemical engineering sense as most of activities of fusion research started on east cost in US in Princeton Plasma Physics Laboratory where physicists and chemical engineers were handling experiments. In physical chemistry sense, He atoms have strong repulsion to $W$ atoms $[80,92]$. This ultra-low solubility forces He atoms to self- 
precipitate into small He bubbles [83] that become nucleation sites [90] for further void growth [93] under radiation induced vacancy supersaturations [94], resulting in material swelling [69, 86, 95] and high temperature He embrittlement [71,96,97], as well as surface blistering [75-78] under low energy and high flux He bombardment [54, 98] at elevated temperatures [99]. This may be mitigated by engineering structures in material which help in outgassing of He. These may be nanochannels, nanocavities and / or vasculated solids. These are purposefully built in material and their type, size, amount, density, configuration, geometry, orientation, and mode of placement heavily effect the degree and control they exercise on final properties (resistance to damage). Other structures such as Helium cavities are also observed which may be suppressed by defect sinks, nano clusters, or interfaces. In physical metallurgy terms, it is a point defect $[100,101]$ in a crystal lattice - a precursor of fuzz $[56,80,102]$ or under dense nanostructure [40] formation. It is produced as a result of self-ejection of $W$ from interstitial positions in its own lattice by He atom or cluster of atoms (usually 9 atoms at $700 \mathrm{~K}$ [40]) (Cluster: $7-8$ atoms (bulk), $<7-8$ atoms (surface) and its bonding with vacancy [88, 103-106] forming a Frenkel pair [107-111]. This is more prominently observed near the surface. In this layer, bubble density and diameter depend on surface temperature and helium flux / fluence [112].

$$
\begin{gathered}
\text { Number density of bubble } N_{d}=f\left(t_{s}, \frac{d f}{d x}\right) \\
\text { Bubble diameter } d=f\left(t_{s}, \frac{d f}{d x}\right)
\end{gathered}
$$

where $t_{s}=$ surface temperature, $\frac{d f}{d x}=$ Helium flux / fluence

Note: This is a plastic deformation in a sense that point defect is formed. However, it occurs athermally (at thermal equilibrium). It is diffusional process and compositional adjustment. This is physico-chemical adjustment. However, later part does not dominate.

This mechanism is tested and proven in conventional nuclear engineering (fission) applications where $\alpha$ and $\beta$ particles, $\nu$ rays and neutron flux strike the material. Plasma does not constitute of aforementioned and thus it is not very applicable mechanism. Selection of suitable crystal lattice which inhibit Frenkel pair [111] generation and promotes host atom self-interstitial solid solution strengthening contributes effectively towards making plasma facing material - subject area of present study. More detailed mechanisms involves loop punching after spontaneous organization of W self-interstitials (SIA) into a prismatic $<111>$ - dislocation loop, ligament thinning [80], crater and nano tendril formation and trap mutation reactions $[80]$

$$
\mathrm{He}_{\mathrm{n}} \mathrm{V}_{\mathrm{m}}+\mathrm{He}------------->\mathrm{He}_{\mathrm{n}+1} \mathrm{~V}_{\mathrm{m}+1}+\mathrm{I}
$$

where $\mathrm{V}=\mathrm{W}$ vacancy, $\mathrm{I}=$ self-interstitial atom. $\mathrm{He}_{3} \mathrm{~V}_{1}$ is a stable cluster. The absence of large $\mathrm{He}_{n} \mathrm{~V}_{\mathrm{m}}$ clusters suppresses fuzz formation [40]. 95.9\% $\mathrm{He}$ is retained in $\mathrm{He}_{3} \mathrm{~V}_{1}$ clusters. Maximum temperature observed so far [40] at which He retention = zero is $2500 \mathrm{~K}$. In this case, unretained / emitted He cannot be trapped but move until they reach the surface and desorb or migrate to bulk.

Various morphologies are also observed such as nano tendrils [91, 113-115], nanochannels [83], large scale nanostructures [116], and structure in equiaxed nanocrystalline tungsten [117]. Role of impurities such as $O$ is also observed and discussed [118]. Various production methods such as powder metallurgy [119] and other routes [120] also play an important part. Extensive simulation studies (such as Molecular dynamics [89], ab-initio [121] have also been carried out which helps. Fuzz itself is a surface phenomenon 
and is only observed in plasmas containing Helium including mixed $\mathrm{He}-\mathrm{H}$ plasmas but never in pure $\mathrm{H}$ or Ne plasmas. It is a strong function of temperature and incident ion energy. In W, it is observed only in temperature range of $900-2000 \mathrm{~K}$ and above threshold incident ion energy of approximately 20 eV and fuzz layer thickness depicts characteristic one - dimensional diffusional growth that scales with square root of fluence. At an ion energy of $10 \mathrm{keV}$ and higher but below $20 \mathrm{KeV}$, a more complex 'coral-like' structure is formed which is not 'fuzz'. This also is undesirable as it deteriorates the properties at much lower incident ion energy than proposed as threshold value. At $\mathrm{T}<900 \mathrm{~K}$ surfaces without any specific or pronounced damage are observed. They appear to be decorated with He bubbles but it is just depiction as no lattice point defect starts at this temperature. At T > $2000 \mathrm{~K}$ only micron-size holes on the surface are formed in the irradiated tungsten which is not fuzz but again is a damage and is undesirable. Materials specially to be used in first wall [12, 17, 28, 85, 119, 122-133], blanket [134-143] and diverter [10, 24, 28, $36,125,144-150]$ of ITER reactor $[10,16,17,24,25,85,129,136,145,147,151-165]$ and experimental $\operatorname{DEMO}[3,4,9,13,19,31,32,36,122,123,133,163,166-173]$ fusion device are important.

\section{Self-interstitial solid solution strengthening - crystallography of plasma facing materials}

Refractory materials such as W have gained popularity to serve as potential plasma facing material [150]. It has high melting point, low activation, good thermo-mechanical properties, good weldability, good corrosion resistance, low sputter erosion/redeposition, low tritium retention/co-deposition and aforementioned nuclear properties. However, upon exposure to plasma, it shows rapid surface degradation exhibiting surface blisters [75-78] and formation of under dense nanostructure - fuzz as described above. It is supposed to happen as $W$ has bcc structure with 12 small tetrahedral interstitial sites and 6 large octahedral interstitial sites $[100,174]$ with lower atomic packing factor and coordination number than fcc (bcc 8, fcc 12) [175], small cation size and a higher tendency for external interstitial atom to occupy 12 small tetrahedral sites $[175,176]$, poor tendency for host / self (W) atom to occupy 6 large octahedral sites, thus poor tendency for self-interstitial solid solution to form and strengthening to occur. Lower atomic packing factor (bcc metals) means atoms are less densely packed in a unit cell and it is easy to eject them from their own lattice e.g. W metal. In these types of metals (e.g. bcc $\alpha$ Fe, W), it is easy to insert external (impurity) atom (e.g. C, N, H) in lattice provided it is of right size, have tendency of preferentially occupy certain sites (12 small tetrahedral sites) and low enough activation energy. Comparative tendency of strengthening by self-interstitial solid solution strengthening is lower and tendency of strengthening by external atom interstitial solid solution strengthening is higher (provided atom is of right size, shape, and valency). (Note: In general, self-diffusion in bcc metals is higher than that in fcc metals at same homologous temperature [177]). Activation energy for self-interstitial formation is approximately $2-5 \times$ larger than for vacancy. This energy can be reduced by so called dumbbell configuration [177-181] in which two atoms share one lattice point; the lattice point is usually at their common center of mass. However, this is independent of the tendency of self-atom (Fe) to occupy interstitial positions and form solid solution).

For interstitial

$$
D^{i}=\frac{a^{2} v_{0} \rho}{6} \exp \left(-\frac{\Delta g_{m}^{i}}{k_{B} T}\right)=D_{0}^{i} \exp \left(-\frac{E_{d}^{i}}{k_{B} T}\right)
$$

where $\rho=$ number of neighboring interstices and $E_{d}^{i}=\Delta h_{m}^{i}$ (Gibbs free energy pf formation)

This may also be represented as [180], 


$$
C_{I}^{e q}=g_{I} \exp \left(-\frac{G_{I}^{F}}{k_{B} T}\right)=g_{I} \exp \left(\frac{S_{I}^{F}}{k_{B}}\right) \exp \left(-\frac{H_{I}^{F}}{k_{B}}\right)
$$

$G_{I}^{F}=$ Gibbs free energy of formation, $S_{I}^{F}$ and $H_{I}^{F}$ the corresponding formation entropy and enthalpy and g, $=$ geometric factor $(\mathrm{fcc}=3)$

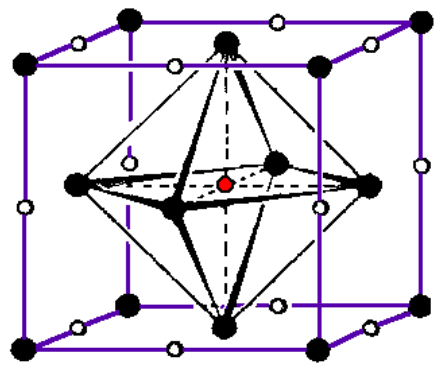

(a)

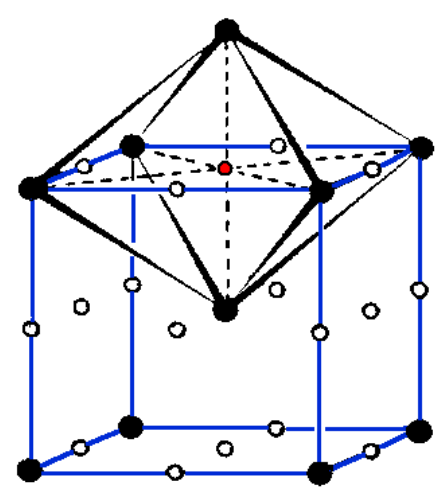

(b)

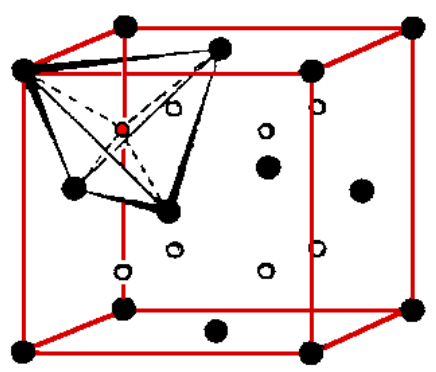

(c)

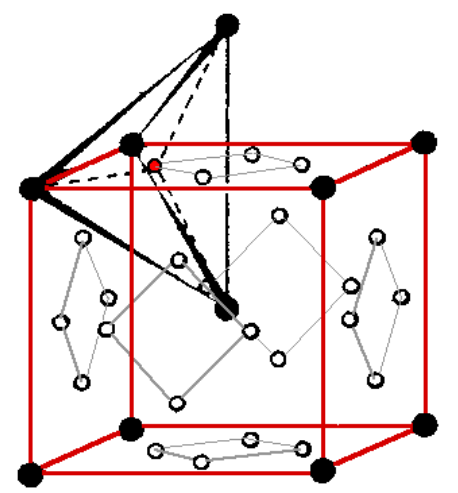

(d)

Figure - 1: (a) Octahedral sites in an fcc lattice. 12 / $4+1=4$ positions per unit cell. (b) Octahedral sites in bcc lattice. $12 / 4+6 / 2=3+3=6$ positions per unit cell. (c) Tetrahedral positions in fcc lattice. 8 positions. (d) Tetrahedral configuration in bcc lattice. $(6.4) / 2=12$ positions per unit cell $[182,183]$.

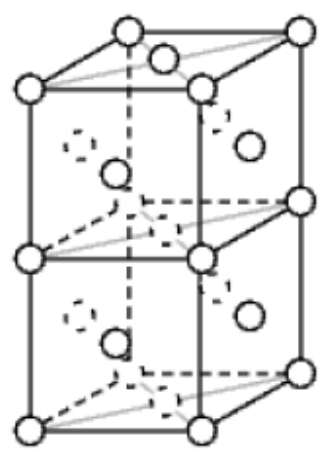

(a)

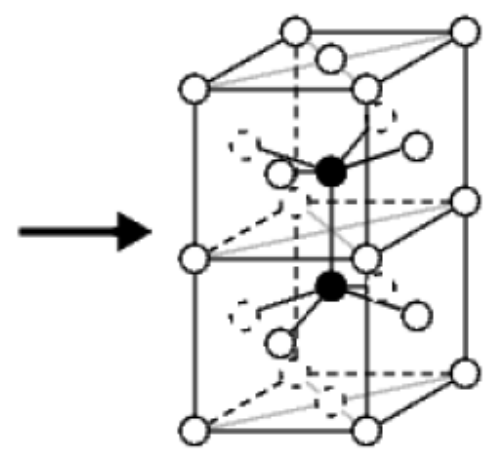

(b)

Figure - 2: (a) FCC 100 dumbbell, (b) Dumbbell configuration of self-interstitial in an fcc lattice [180]. 
Further, W has high radius (139 pm) than iron (126 pm) which also restricts formation of interstitial solid solution. It also has very high staking fault energy at room temperature which requires a lot of force before considerable plastic deformation. Plastic deformation happens along certain planes of highest possible planar density [184]. Various complimentary surface engineering techniques such as physical vapor deposition is applied to counter this. These form surface architecture (nanochannels) and vasculated solids which help escape of He hence hinder degradation. However, this is additional expensive step without understanding underlying phenomena. In essence, bubble is not a physical feature and any generation of nanochannels will not help their escape. Fcc iron carbon alloys (austenitic stainless steels AISI / SAE 321) are proposed as suitable candidate. Along with their fcc structure, they have excellent corrosion resistance, high thermal conductivity, and non-magnetic properties. Careful control of their bulk and surface microstructure by alloying during melting and casting and followed by heat treatment is proposed to yield excellent architecture which not only inhibit Frankel pair generation but will also provide paths (suitable sites) for movement of any of this point defect in lattice, its bulk assimilation and surface annihilation. Historically, it is also a material of choice $[185,186]$.

\section{Size of interstitial sites in a lattice - Largest interstitial void radius in fcc lattice}

Interstitial solid solutions are those in which the solute atoms occupy the interstitial positions (holes between the atoms) in the crystal lattice of the solute. Interstitial solid solutions always have limited solubility of the solute. One of the requirements of measurable solubility is that solute atoms must be small enough to fit into the interstitial positions of solvent. Electronegativity differences are also important. For example, carbon shows measurable interstitial solubility in Iron while $\mathrm{O}_{2}$ and $\mathrm{F}_{2}$ do not. Even though atoms are smaller than C. At above lower critical line in Fe-C diagram, Fe can adopt a face centered cubic $(\mathrm{fcc})$ structure. Radius of the largest interstitial void in this lattice at $(1 / 2,0,0)$, $(0,1 / 2,0),(0,0,1 / 2)$ type positions may be calculated as. (The atomic radius of Fe $=0.129 \mathrm{~nm}$ ).

Let the radius of an Fe atom be $R$ and that of the interstitial atom at the position $(0,1 / 2,0)$ be $r$. Then from the figure 3 we see,

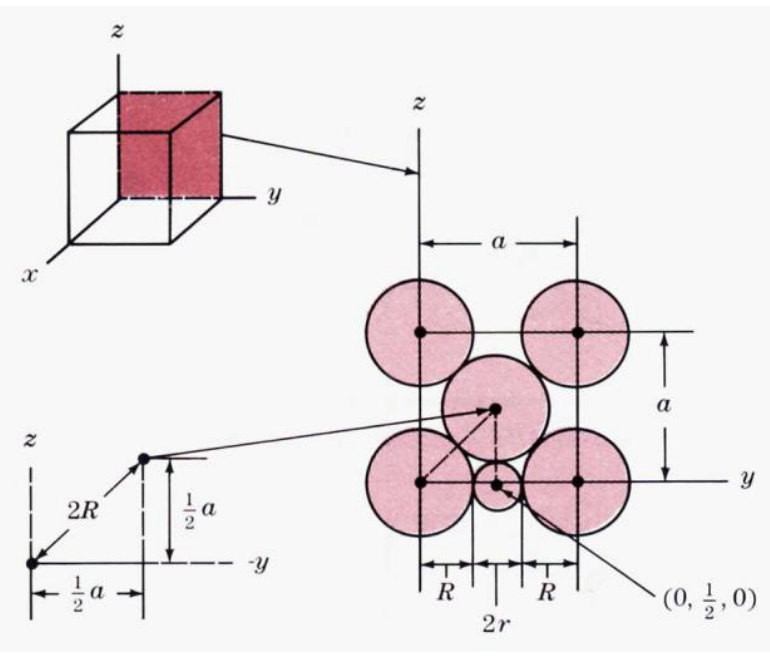

Figure - 3: Schematic of interstitial void in fcc lattice

$$
2 \mathrm{R}+2 \mathrm{r}=\mathrm{a}
$$


In addition, from geometry we see that

$$
\begin{gathered}
(2 R)^{2}=(1 / 2 a)^{2}+(1 / 2 a)^{2} \\
4 R^{2}=1 / 4 a^{2}+1 / 4 a^{2} \\
(2 R)^{2}=\frac{1}{2} a^{2}
\end{gathered}
$$

Solving for $a$ give

$$
\begin{aligned}
(2 R) & =\left(\frac{1}{\sqrt{2}}\right) a \text { or } \\
a & =2 \sqrt{2} R
\end{aligned}
$$

Hence,

$$
2 R+2 r=2 \sqrt{2} R
$$

or

$$
\begin{aligned}
& r=(\sqrt{2}-1) R=0.414 \mathrm{R} \\
& r=0.414(0.129 \mathrm{~nm})=0.053 \mathrm{~nm}
\end{aligned}
$$

By comparison, the radius of a carbon atom is $0.075 \mathrm{~nm}$. Hence, interstitial $\mathrm{C}$ atom in an fcc Fe crystal will cause considerable local distortion but still the criteria of $r / R<0.59$ is satisfied $[187,188]$. Radius of Fe atom $0.129 \mathrm{~nm}$. This atom will cause a lot of local distortion in fcc Fe crystal. Thus, self-interstitial solid solution strengthening is possible with a lot of local distortion.

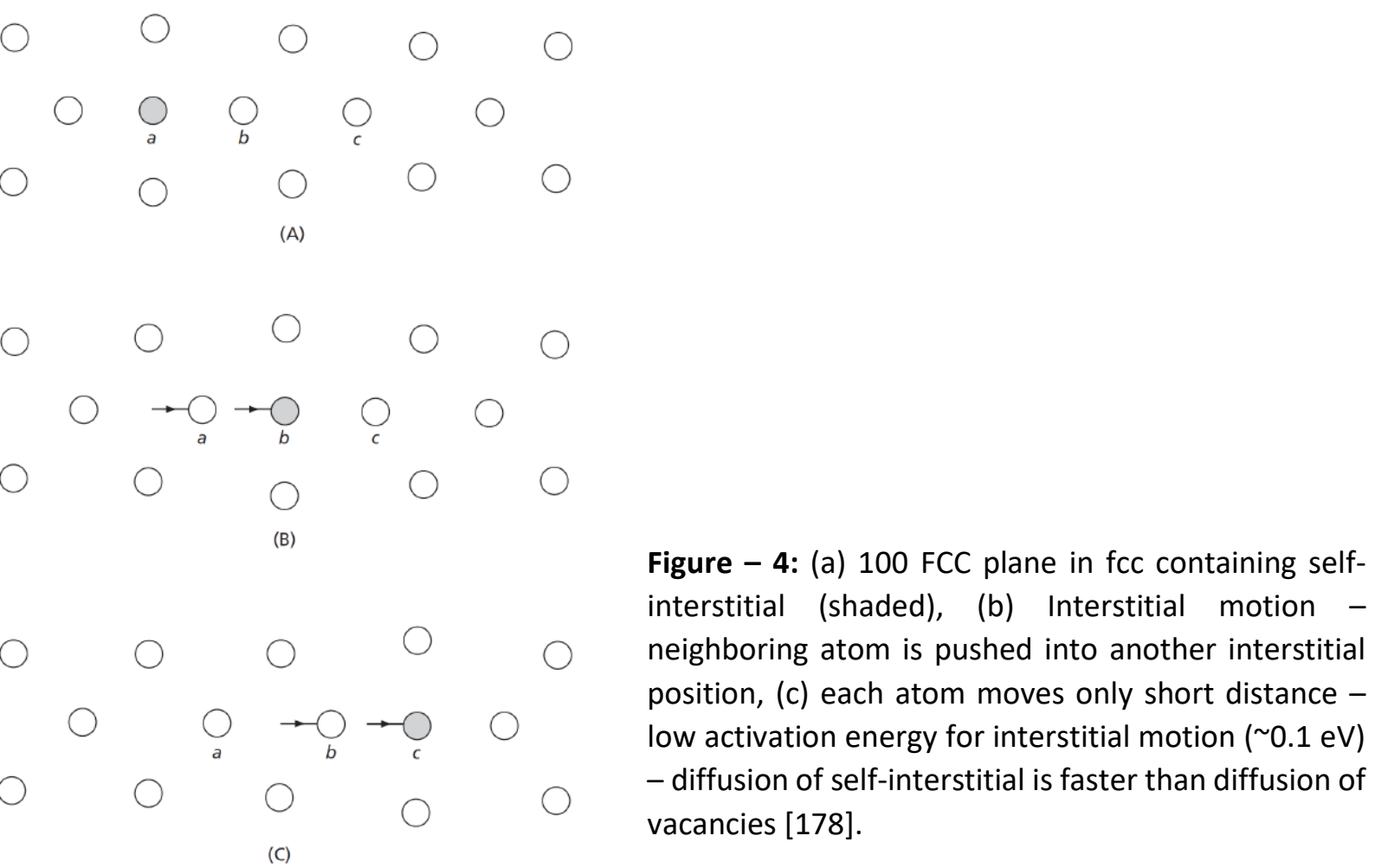

Figure - 4: (a) 100 FCC plane in fcc containing selfinterstitial (shaded), (b) Interstitial motion neighboring atom is pushed into another interstitial position, (c) each atom moves only short distance low activation energy for interstitial motion ( $0.1 \mathrm{eV})$ diffusion of self-interstitial is faster than diffusion of 


\section{Self-diffusion coefficient}

Self-diffusion is commonly observed in pure metals and is mainly governed by vacancy mechanisms. It is seldom observed in alloys (such as steels) hence corresponding self-diffusion coefficient is seldom measured. Various models such as Zener model [189], cB $\Omega$ [190-192] are employed to measure this.

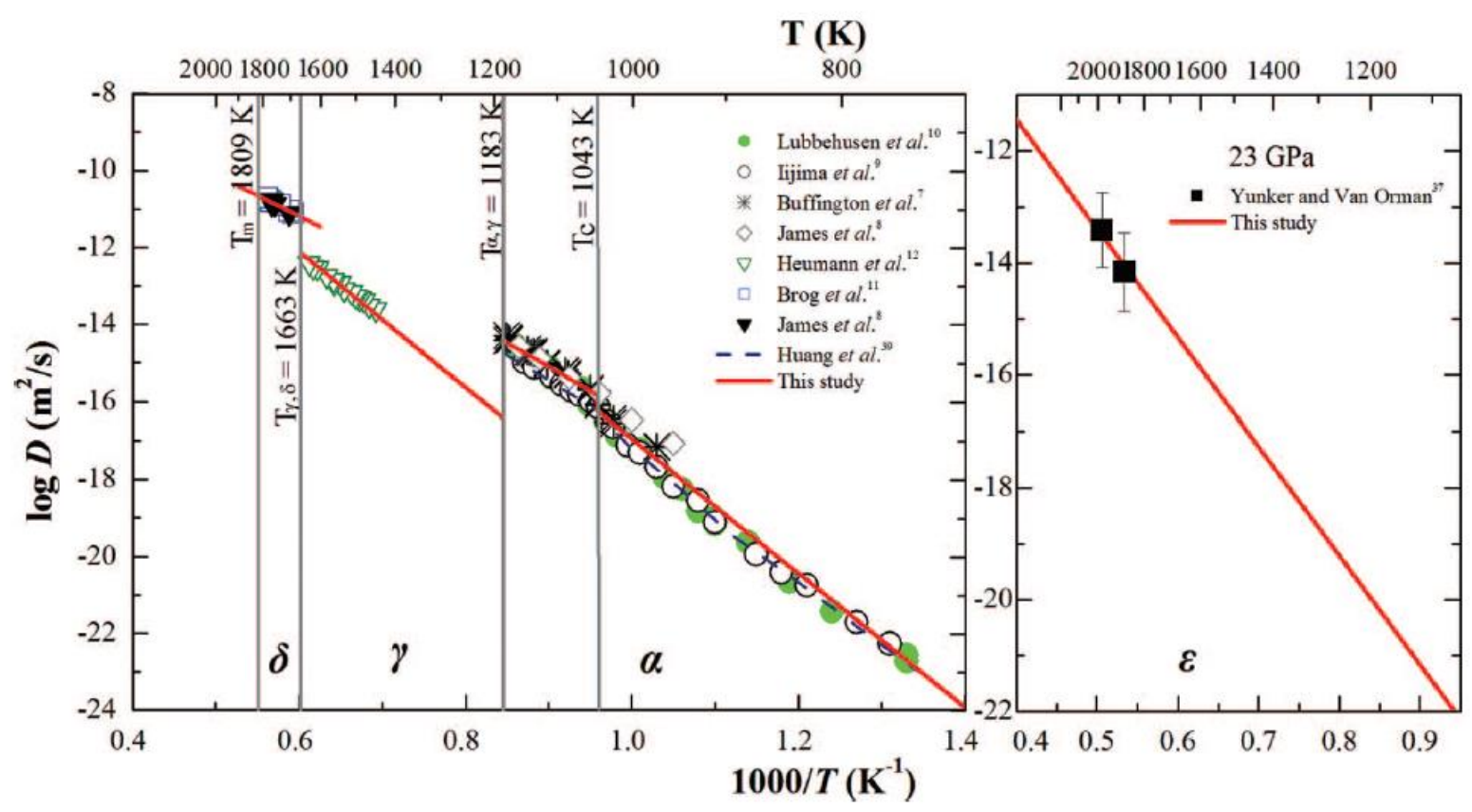

Figure - 5: Predicted temperature dependence of calculated self-diffusion coefficients derived from $\mathrm{cB} \Omega$ model (red lines) Vs published experimental data in $\alpha, \delta, \curlyvee$ and $\varepsilon-F e$ [190-192].

Clearly, Self-diffusion coefficient of Fe in bcc $(\alpha)$ iron is higher than in $f c c(\gamma)$ Fe. This is because of reasons mentioned earlier (Atomic packing factor of bcc is lower than fcc. Thus, it is easy to insert host / self (Fe) atom in its lattice irrespective of position).

\section{Other plasma facing materials and conditions}

Besides W, Be and carbon (in particular, fiber reinforced graphite) is the most frequently used PFM in today's magnetic confinement experiment. Depending on the selected fiber type and architecture, carbon fiber reinforced graphite can be manufactured with thermal conductivities equal to or higher than that of copper (up to about $400 \mathrm{~W} / \mathrm{m} / \mathrm{K}$ )

$$
\mathrm{K}_{\mathrm{cfr}} \geq \mathrm{k}_{\mathrm{c}}
$$

However, such an excellent thermal conductivity will degrade rapidly under the influence of energetic neutrons. In D - T burning fusion reactors with carbon walls tritium containing hydrocarbon deposits are formed on all in vessel components. This will finally result in an inacceptable tritium inventory in the fusion reactor under current licensing laws and limits or

1) Tritium $\left({ }^{2} \mathrm{H}_{1}\right)$ is retained in crystal lattice of Carbon hexagonal close packed structure.

2) This result in ${ }^{2} \mathrm{H}_{1}$ rich inventory. 
For these two reasons, carbon has been discarded as a PFM for ITER. A study details thermal conditions experienced by $W$ plasma facing material during operation [193]. These are, $W$ armor plate (Type: Castellated, $\mathrm{W}=4 \mathrm{~mm}, \mathrm{H}=5,8-10 \mathrm{~mm}, \mathrm{Th}=10 \mathrm{~mm}$, gap width $=0.5 \mathrm{~mm}$ (Figure 6)), base surfacetemperature $400-780^{\circ} \mathrm{C}$, steady state load with power density $5-10 \mathrm{MW} / \mathrm{m}^{2}$, applied transient heat load $0.2 \mathrm{GW} / \mathrm{m}^{2}$, time $0.5 \mathrm{~ms}$ in order to avoid plastic deformation of W. However, actual conditions are harsh and plastic deformation happens as discussed above.

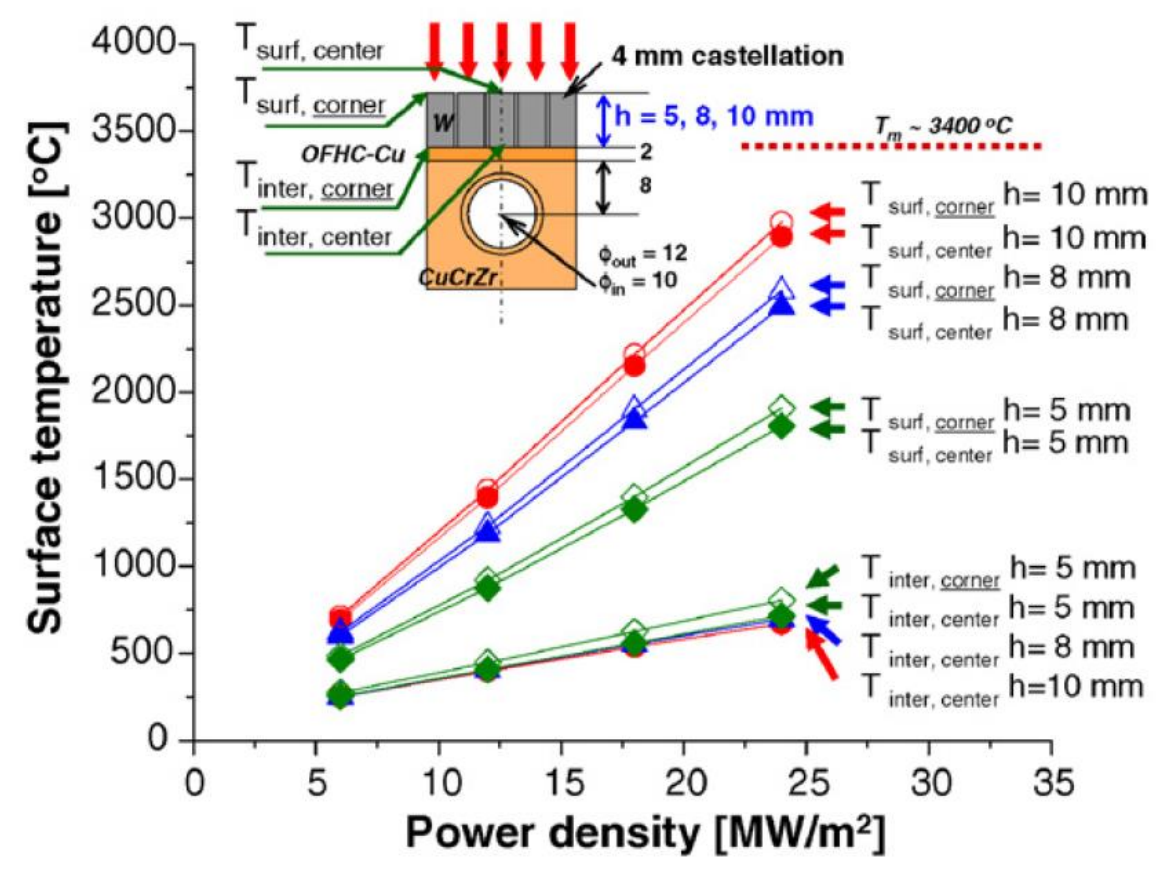

Figure - 6: Surface temperature Vs Power density for steady state heat transfer analysis of divertor castellated W plate using ANSYS [193].

Clearly, it can be seen, surface temperature reaches around $2500^{\circ} \mathrm{C}$ at power density of $20 \mathrm{MW} / \mathrm{m}^{2}$ and interface temperature exceeds $650^{\circ} \mathrm{C}$ (exceeding operating temperature of $\mathrm{Cu}$ ). Thus, is not desirable. Other designs include, $5.5 \mathrm{~cm}$ thick divertor consists of $\sim 40 \% \mathrm{~W}-1.1 \mathrm{TiC}$ alloy, $\sim 12 \%$ ODS ferritic steel, and $18 \%$ He coolant, by volume [194]. The $14 \mathrm{MeV}$ source neutrons will activate the armor and generate radioactive materials at the end of the divertor service lifetime $[97,195]$. 


\section{Manufacturing, processing, and characterization}

\subsection{Phase diagram}

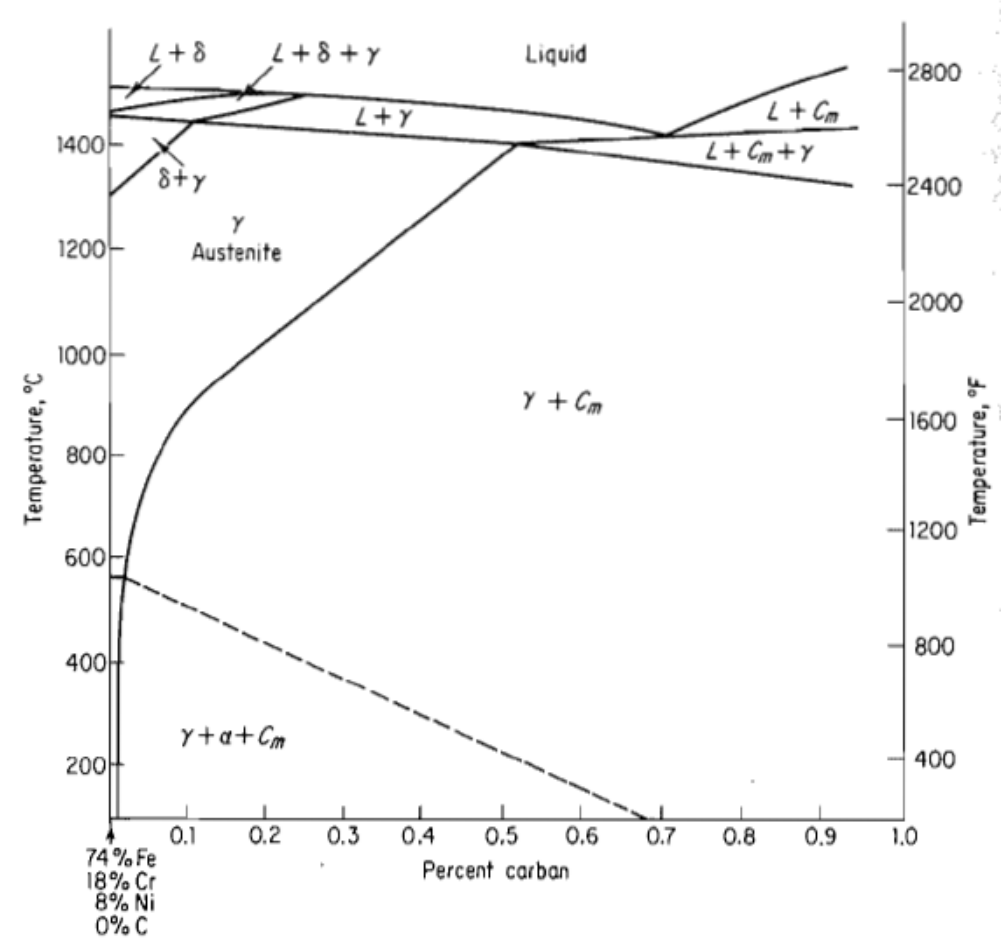

Figure - 7: Tentative cross section diagram showing trend of reactions in steels alloyed with $18 \% \mathrm{Cr}, 8 \%$ Ni $([100,196]$

Above modified phase diagram of stainless steel is used to identify chemical composition, temperatures, and phases to be formed in alloy. Typical composition of $321 \mathrm{S.S}$ is as follows

Table - 1: Composition of 321 S.S

\begin{tabular}{|l|l|l|l|l|l|l|l|l|l|l|l|}
\hline Alloy & Designation & $\mathrm{C}$ & $\mathrm{N}$ & $\mathrm{Cr}$ & $\mathrm{Ni}$ & $\mathrm{Mo}$ & $\mathrm{Mn}$ & $\mathrm{Si}$ & Other & Other & Other \\
\hline 321 & $\mathrm{~S} 32100$ & 0.05 & 0.01 & 17.7 & 9.1 & 0.03 & 1.0 & 0.45 & $0.001 \mathrm{~S}$ & $0.03 \mathrm{P}$ & $0.4 \mathrm{Ti}$ \\
\hline
\end{tabular}

Typical production cycle consists of melting and permanent mold casting of plates using air induction of vacuum induction melting and casting furnace. A vacuum induction furnace exercises better control on chemical composition and resulting properties. This may be substituted with a better melting, control and use of fluxes during air induction furnace but it may result in poor quality both during melting and casting (such as air entrapment, misruns, inclusions, pin holes, gas holes, shrinkage, hot tears and surface degradation along with improper and poor control on chemical composition).

\subsection{Heat treatment}

Stabilizing heat treatment is performed to precipitate all carbon as TiC in 321 S.S (Ti variant) and prevent formation of $\mathrm{Cr}_{23} \mathrm{C}_{6}$ (sensitization). For titanium carbide, solubility may be determined from. 


$$
\log [T i][C]=2.97-\frac{6780}{T}
$$

Typical heat treatment cycle is

Heat $=1625 \mathrm{~F}$, Hold $=4 \mathrm{hrs}$ and cool

A detailed cycle may be obtained from below chart (Figure 8) based on carbon content of material.

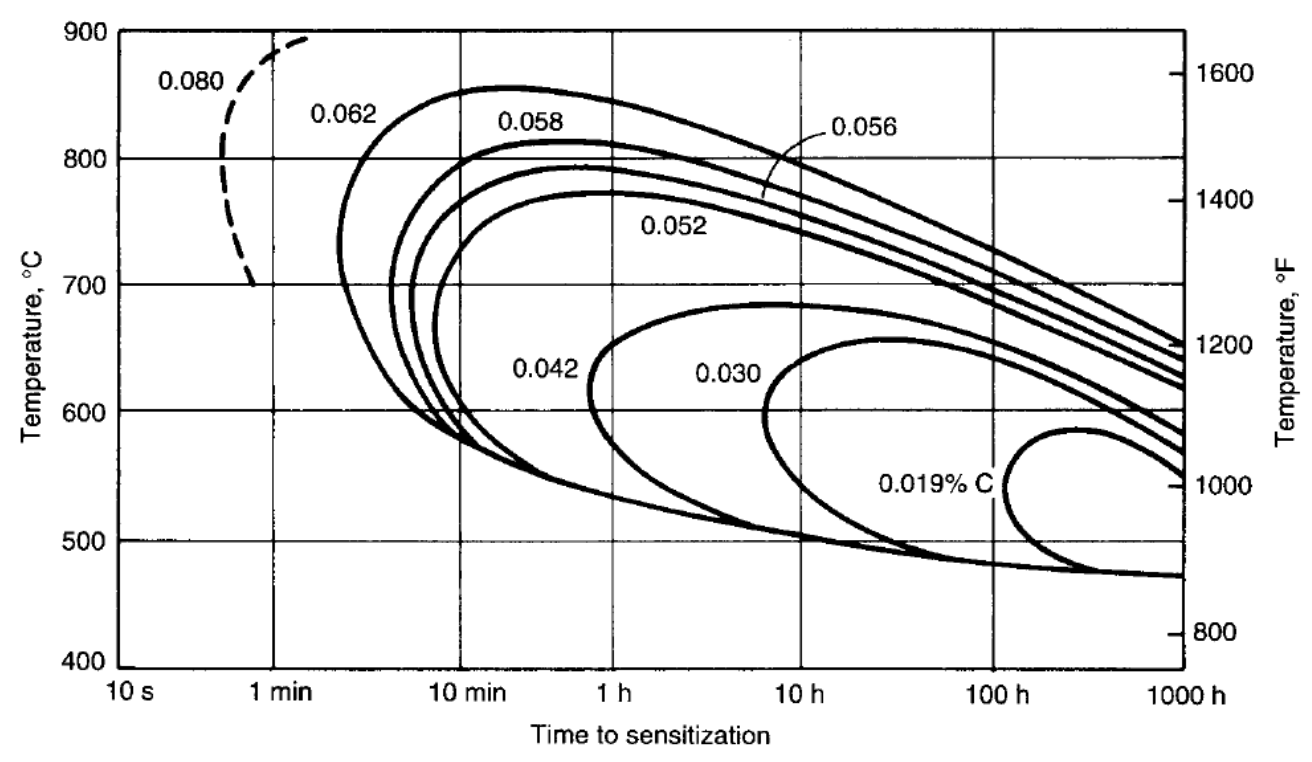

Figure - 8: The precipitation rates of $\mathrm{Cr}_{23} \mathrm{C}_{6}$ as a function of carbon content.

Surface heat treatment cycle (flame hardening) depends on part geometry and part thickness. The design calls for $10 \mathrm{~mm}$ thick plate directly acting as plasma facing material. In diverter region, a $0.5 \mathrm{~cm}$ thick sacrificial armor layer is used to protect the divertor during operation. Flame is operated at above lower critical line $\left(A_{3}\right)$ for subject material. For a typical composition and above section thickness below cycle may be followed,

Heat $=700^{\circ} \mathrm{C}$, Hold $(60-120$ seconds intermittently). A proper heat transfer analysis may provide actual time and temperature $[197,198]$.

\subsection{Characterization}

Bulk and surface characterizations are performed to assess and ascertain material properties prior and post testing. This includes detailed physical, chemical, mechanical, and nuclear property determination. Some of these are listed as under. Physical: SEM (SE and BSE), EDX (Chemical composition), WDX (phase), Thickness measurement (Ultrasonic probe during Non-destructive testing (NDT)), Mechanical: Yield strength, ultimate tensile strength, parentage elongation, hardness, and creep testing. Nuclear: Amount of eroded material, Optical emission spectroscopy (OES), Target mass loss technique, In-situ Quartz microbalance (QMB), Deuterium retention, Thermal desorption spectrometry and Nuclear reaction analysis. 


\section{Conclusion}

1. Bubble is identified as crystal lattice (point) defect - not a physical / geometric feature.

2. A crystal lattice having the tendency to form self-interstitial solid solution has been identified.

3. FCC lattice $y$ - iron is identified as suitable crystal lattice.

4. Insertion of Fe $(0.129 \mathrm{~nm})$ in interstitial site $(0.053 \mathrm{~nm})$ will form interstitial solid solution with large lattice strain.

5. 321 Stainless steel is proposed as suitable material.

Self-interstitial solid solution strengthening is possible with a lot of local distortion which may be removed by surface heat treatment after stabilizing heat treatment.

\section{References}

1. Rubel, M., Fusion Neutrons: Tritium Breeding and Impact on Wall Materials and Components of Diagnostic Systems. Journal of Fusion Energy, 2019. 38(3): p. 315-329.

2. Abdou, M., et al., Recent progress in design studies for tokamak demonstration and commercial power plants, in Fusion Reactor Design and Technology. 1983, International Atomic Energy Agency Vienna. p. 231-272.

3. Bachmann, C., et al., Initial DEMO tokamak design configuration studies. Fusion Engineering and Design, 2015. 98-99: p. 1423-1426.

4. Brown, R. and M. Porton. The development of a methodology to allocate RAMI requirements to DEMO: The development of design tools \& methodologies for DEMO in Europe. in 2013 IEEE 25th Symposium on Fusion Engineering (SOFE). 2013.

5. Chen, H., et al., Magnetohydrodynamic experimental design and program for Chinese liquid metal LiPb experimental loop DRAGON-IV. Fusion Engineering and Design, 2010. 85(10): p. 1742-1746.

6. Enoeda, M., et al., Design and technology development of solid breeder blanket cooled by supercritical water in Japan. Nuclear Fusion, 2003. 43(12): p. 1837-1844.

7. Federici, G., et al., DEMO design activity in Europe: Progress and updates. Fusion Engineering and Design, 2018. 136: p. 729-741.

8. Federici, G., et al., An overview of the EU breeding blanket design strategy as an integral part of the DEMO design effort. Fusion Engineering and Design, 2019. 141: p. 30-42.

9. Federici, G., et al., Overview of EU DEMO design and R\&D activities. Fusion Engineering and Design, 2014. 89(7): p. 882-889.

10. Hirai, T., et al., ITER tungsten divertor design development and qualification program. Fusion Engineering and Design, 2013. 88(9): p. 1798-1801.

11. Ho, S.K. and M.A. Abdou, Exploration and assesment of design windows for a Tokamak-based volumetric neutron source. Fusion Engineering and Design, 1996. 31(4): p. 323-332.

12. Igitkhanov, Y., R. Fetzer, and B. Bazylev, Effect of design geometry of the demo first wall on the plasma heat load. Nuclear Materials and Energy, 2016. 9: p. 560-564.

13. Konishi, S., S. Nishio, and K. Tobita, DEMO plant design beyond ITER. Fusion Engineering and Design, 2002. 63-64: p. 11-17.

14. Lei, M., et al., Design and thermal-hydraulic evaluation of helium-cooled ceramic breeder blanket for China fusion engineering test reactor. International Journal of Energy Research, 2018. 42(4): p. 1657-1663.

15. Leshukov, A.Y., et al., Design development and analytical assessment of LLCB TBM in Russian Federation during 2012-2013. Fusion Engineering and Design, 2014. 89(7): p. 1232-1240. 
16. Lister, J.B., et al., The ITER CODAC conceptual design. Fusion Engineering and Design, 2007. 82(5): p. 1167-1173.

17. Mitteau, R., et al., Heat loads and shape design of the ITER first wall. Fusion Engineering and Design, 2010. 85(10): p. 2049-2053.

18. Moeslang, A., et al., The IFMIF test facilities design. Fusion Engineering and Design, 2006. 81(8): p. 863-871.

19. Moscato, I., et al., Preliminary design of EU DEMO helium-cooled breeding blanket primary heat transfer system. Fusion Engineering and Design, 2018. 136: p. 1567-1571.

20. Norajitra, P., et al., Conceptual design of the dual-coolant blanket in the frame of the EU power plant conceptual study. Fusion Engineering and Design, 2003. 69(1): p. 669-673.

21. Perrault, D., Safety issues to be taken into account in designing future nuclear fusion facilities. Fusion Engineering and Design, 2016. 109-111: p. 1733-1738.

22. Petti, D.A., et al., ARIES-AT safety design and analysis. Fusion Engineering and Design, 2006. 80(1): p. 111-137.

23. Pitts, R.A., et al., Physics basis and design of the ITER plasma-facing components. Journal of Nuclear Materials, 2011. 415(1, Supplement): p. S957-S964.

24. Pitts, R.A., et al., A full tungsten divertor for ITER: Physics issues and design status. Journal of Nuclear Materials, 2013. 438: p. S48-S56.

25. Rampal, G., et al., HCLL TBM for ITER-design studies. Fusion Engineering and Design, 2005. 75-79: p. 917-922.

26. Sagara, A., et al., Innovative Liquid Breeder Blanket Design Activities in Japan. Fusion Science and Technology, 2005. 47(3): p. 524-529.

27. Seki, Y., Fusion reactor design and technology program in Japan. Fusion Engineering and Design, 1994. 25(1): p. 49-66.

28. Sergeev, V.Y., et al., Conceptual design of divertor and first wall for DEMO-FNS. Nuclear Fusion, 2015. 55(12): p. 123013.

29. Song, Y.T., et al., Concept Design of CFETR Tokamak Machine. IEEE Transactions on Plasma Science, 2014. 42(3): p. 503-509.

30. Tillack, M.S., et al., Configuration and engineering design of the ARIES-RS tokamak power plant. Fusion Engineering and Design, 1997. 38(1): p. 87-113.

31. Tobita, K., G. Federici, and K. Okano, Research and development status on fusion DEMO reactor design under the Broader Approach. Fusion Engineering and Design, 2014. 89(9): p. 1870-1874.

32. Tobita, K., et al., Design study of fusion DEMO plant at JAERI. Fusion Engineering and Design, 2006. 81(8): p. 1151-1158.

33. Voss, G.M., et al., Conceptual design of a component test facility based on the spherical tokamak. Fusion Engineering and Design, 2008. 83(10): p. 1648-1653.

34. Wan, B., et al., Physics Design of CFETR: Determination of the Device Engineering Parameters. IEEE Transactions on Plasma Science, 2014. 42(3): p. 495-502.

35. Wu, Y., Design status and development strategy of China liquid lithium-lead blankets and related material technology. Journal of Nuclear Materials, 2007. 367-370: p. 1410-1415.

36. You, J.H., et al., European DEMO divertor target: Operational requirements and material-design interface. Nuclear Materials and Energy, 2016. 9: p. 171-176.

37. Zheng, J., et al., Concept design of CFETR superconducting magnet system based on different maintenance ports. Fusion Engineering and Design, 2013. 88(11): p. 2960-2966.

38. Zheng, J., et al. Concept design of hybrid superconducting magnet for CFETR Tokamak reactor. in 2013 IEEE 25th Symposium on Fusion Engineering (SOFE). 2013.

39. Zhuang, G., et al., Progress of the CFETR design. Nuclear Fusion, 2019. 59(11): p. 112010. 
40. Valles, G., et al., Temperature dependence of underdense nanostructure formation in tungsten under helium irradiation. Journal of Nuclear Materials, 2017. 490: p. 108-114.

41. Ying, A.Y. and A.A. Gaizer, The effects of imperfect insulator coatings on MHD and heat transfer in rectangular ducts. Fusion Engineering and Design, 1995. 27: p. 634-641.

42. Ying, A.Y. and M.A. Abdou, Application of reliability analysis method to fusion component testing. Fusion Engineering and Design, 1995. 27: p. 191-197.

43. You, J.H. and M. Miskiewicz, Material parameters of copper and CuCrZr alloy for cyclic plasticity at elevated temperatures. Journal of Nuclear Materials, 2008. 373(1): p. 269-274.

44. Wurster, S., et al., Fracture behaviour of tungsten-vanadium and tungsten-tantalum alloys and composites. Journal of Nuclear Materials, 2011. 413(3): p. 166-176.

45. Zinkle, S.J. and J.T. Busby, Structural materials for fission \& fusion energy. Materials Today, 2009. 12(11): p. 12-19.

46. Young, G.A., et al., Welds for Nuclear Systems $\vec{s}$, in Reference Module in Materials Science and Materials Engineering. 2019, Elsevier.

47. Zenobia, S.J., L.M. Garrison, and G.L. Kulcinski, The response of polycrystalline tungsten to $30 \mathrm{keV}$ helium ion implantation at normal incidence and high temperatures. Journal of Nuclear Materials, 2012. 425(1): p. 83-92.

48. Yoshida, N., et al., Impact of low energy helium irradiation on plasma facing metals. Journal of Nuclear Materials, 2005. 337-339: p. 946-950.

49. Yi, X., et al., A study of helium bubble production in 10keV He+ irradiated tungsten. Fusion Engineering and Design, 2017. 125: p. 454-457.

50. Yin, $\mathrm{H}$., et al., Recent studies of tungsten-based plasma-facing materials in the linear plasma device STEP. Tungsten, 2019. 1(2): p. 132-140.

51. Khan, A., et al., Effect of rhenium addition on tungsten fuzz formation in helium plasmas. Journal of Nuclear Materials, 2016. 474: p. 99-104.

52. Gai, X., et al., Helium bubbles in bcc Fe and their interactions with irradiation. Journal of Nuclear Materials, 2015. 462: p. 382-390.

53. Xu, C. and W. Wang, Simulation Study of Helium Effect on the Microstructure of Nanocrystalline Body-Centered Cubic Iron. Materials, 2019. 12(1).

54. Novakowski, T.J., J.K. Tripathi, and A. Hassanein, Effect of high-flux, low-energy He+ ion irradiation on Ta as a plasma-facing material. Scientific Reports, 2016. 6(1): p. 39746.

55. Dias, M., et al., Helium and deuterium irradiation effects in $W$-Ta composites produced by pulse plasma compaction. Journal of Nuclear Materials, 2017. 492: p. 105-112.

56. Kajita, S., et al., Fuzzy nanostructure growth on Ta/Fe by He plasma irradiation. Scientific Reports, 2016. 6(1): p. 30380.

57. Fiflis, P., et al., Nanostructuring of Palladium with Low-Temperature Helium Plasma. Nanomaterials, 2015. 5(4).

58. Fan, C., et al., Dual Beam In Situ Radiation Studies of Nanocrystalline Cu. Materials, 2019. 12(17).

59. Su, Q., et al., Resistance to Helium Bubble Formation in Amorphous SiOC/Crystalline Fe Nanocomposite. Materials, 2019. 12(1).

60. Yang, X., et al., Tungsten-potassium: a promising plasma-facing material. Tungsten, 2019. 1(2): p. 141-158.

61. van der Schaaf, B., et al., The development of EUROFER reduced activation steel. Fusion Engineering and Design, 2003. 69(1): p. 197-203.

62. Tan, L., et al., Development of nanoprecipitates-strengthened advanced ferritic alloys for nuclear reactor applications. 2019: United States.

63. Tavassoli, A.A.F., et al., Current status and recent research achievements in ferritic/martensitic steels. Journal of Nuclear Materials, 2014. 455(1): p. 269-276. 
64. Reimann, J., et al., Thermomechanics of solid breeder and Be pebble bed materials. Fusion Engineering and Design, 2002. 61-62: p. 319-331.

65. van Til, S., et al., Evolution of beryllium pebbles (HIDOBE) in long term, high flux irradiation in the high flux reactor. Fusion Engineering and Design, 2011. 86(9): p. 2258-2261.

66. Zhang, C., A. Ying, and M.A. Abdou, FEM Modeling of Pebble Bed/Structural Wall Separation. Fusion Science and Technology, 2015. 68(3): p. 612-617.

67. Ying, A., et al., Status of ceramic breeder pebble bed thermo-mechanics R\&D and impact on breeder material mechanical strength. Fusion Engineering and Design, 2012. 87(7): p. 1130-1137.

68. Fedorov, A.V., et al., Post irradiation characterization of beryllium and beryllides after high temperature irradiation up to 3000appm helium production in HIDOBE-01. Fusion Engineering and Design, 2016. 102: p. 74-80.

69. Snead, L.L., T.D. Burchell, and Y. Katoh, Swelling of nuclear graphite and high quality carbon fiber composite under very high irradiation temperature. Journal of Nuclear Materials, 2008. 381(1): p. 55-61.

70. Brooks, J.N., et al., Plasma-facing material alternatives to tungsten. Nuclear Fusion, 2015.55.

71. Rowcliffe, A.F., et al., Materials-engineering challenges for the fusion core and lifetime components of the fusion nuclear science facility. Nuclear Materials and Energy, 2018. 16: p. 8287.

72. Odette, G.R., M.J. Alinger, and B.D. Wirth, Recent Developments in Irradiation-Resistant Steels. Annual Review of Materials Research, 2008. 38(1): p. 471-503.

73. Mansur, L.K., et al., Control of helium effects in irradiated materials based on theory and experiment. Journal of Nuclear Materials, 1986. 141-143: p. 633-646.

74. Beyerlein, I.J., et al., Radiation damage tolerant nanomaterials. Materials Today, 2013. 16(11): p. 443-449.

75. Bauer, J., et al., Influence of near-surface blisters on deuterium transport in tungsten. Nuclear Fusion, 2017. 57(8): p. 086015.

76. Chen, W.Q., et al., Irradiation hardening induced by blistering in tungsten due to low-energy high flux hydrogen plasma exposure. Journal of Nuclear Materials, 2019. 522: p. 11-18.

77. Gavish Segev, I., et al., Hydrogen blister formation in single crystal and polycrystalline tungsten irradiated by MeV protons. Journal of Nuclear Materials, 2019. 513: p. 209-220.

78. Zhou, H.-B., et al., Towards suppressing $H$ blistering by investigating the physical origin of the HHe interaction in W. Nuclear Fusion, 2010. 50(11): p. 115010.

79. Baldwin, M.J. and R.P. Doerner, Formation of helium induced nanostructure 'fuzz' on various tungsten grades. Journal of Nuclear Materials, 2010. 404(3): p. 165-173.

80. Dasgupta, D., et al., On the origin of 'fuzz' formation in plasma-facing materials. Nuclear Fusion, 2019. 59(8): p. 086057.

81. Doerner, R.P., M.J. Baldwin, and P.C. Stangeby, An equilibrium model for tungsten fuzz in an eroding plasma environment. Nuclear Fusion, 2011. 51(4): p. 043001.

82. Doerner, R.P., et al., Motion of $W$ and He atoms during formation of W fuzz. Nuclear Fusion, 2018. 58(6): p. 066005.

83. Chen, D., et al., Self-organization of helium precipitates into elongated channels within metal nanolayers. Science Advances, 2017. 3(11): p. eaao2710.

84. Dechaumphai, E., et al., Near-surface thermal characterization of plasma facing components using the 3-omega method. Journal of Nuclear Materials, 2014. 455(1): p. 56-60.

85. Huang, S., Y. Zhao, and W. Wang, Numerical Evaluation on Heat Shock Resistance of Two ITER-Like First Wall Mockups. Journal of Fusion Energy, 2015. 34(6): p. 1465-1477. 
86. Zhang, F., et al., Swelling and Helium Bubble Morphology in a Cryogenically Treated FeCrNi Alloy with Martensitic Transformation and Reversion after Helium Implantation. Materials, 2019. 12(17).

87. Lukacs, M. and L.G. Williams, Nuclear safety issues for fusion power plants. Fusion Engineering and Design, 2020. 150: p. 111377.

88. Perez, D., et al., The mobility of small vacancy/helium complexes in tungsten and its impact on retention in fusion-relevant conditions. Scientific Reports, 2017. 7(1): p. 2522.

89. Sandoval, L., et al., An Overview of Recent Standard and Accelerated Molecular Dynamics Simulations of Helium Behavior in Tungsten. Materials, 2019. 12(16).

90. Taylor, C.A., et al., Investigating Helium Bubble Nucleation and Growth through Simultaneous InSitu Cryogenic, Ion Implantation, and Environmental Transmission Electron Microscopy. Materials, 2019. 12(16).

91. Wang, K., et al., Morphologies of tungsten nanotendrils grown under helium exposure. Scientific Reports, 2017. 7(1): p. 42315.

92. $\mathrm{Li}, \mathrm{X} .-\mathrm{C}$., et al., Helium defects interactions and mechanism of helium bubble growth in tungsten: A molecular dynamics simulation. Journal of Nuclear Materials, 2014. 451(1): p. 356-360.

93. Kim, I.S., et al., Defect and void evolution in oxide dispersion strengthened ferritic steels under 3.2 $\mathrm{MeV} \mathrm{Fe+} \mathrm{ion} \mathrm{irradiation} \mathrm{with} \mathrm{simultaneous} \mathrm{helium} \mathrm{injection.} \mathrm{Journal} \mathrm{of} \mathrm{Nuclear} \mathrm{Materials,} 2000$. 280(3): p. 264-274.

94. Trinkaus, H. and B.N. Singh, Helium accumulation in metals during irradiation - where do we stand? Journal of Nuclear Materials, 2003. 323(2): p. 229-242.

95. Kajita, S., et al., Growth of multifractal tungsten nanostructure by He bubble induced directional swelling. New Journal of Physics, 2015. 17(4): p. 043038.

96. Abernethy, R.G., Predicting the performance of tungsten in a fusion environment: a literature review. Materials Science and Technology, 2017. 33(4): p. 388-399.

97. Linke, J., et al., Challenges for plasma-facing components in nuclear fusion. Matter and Radiation at Extremes, 2019. 4(5): p. 056201.

98. Yang, Q., et al., Nanostructured fuzz growth on tungsten under low-energy and high-flux He irradiation. Scientific Reports, 2015. 5(1): p. 10959.

99. Wang, Y. and K. Hattar, Special Issue: Radiation Damage in Materials-Helium Effects. Materials (Basel), 2020. 13(9).

100. Smallman, R.E. and R.J. Bishop, Modern Physical Metallurgy and Materials Engineering. 1999: Elsevier Science.

101. Dieter, G.E. and D. Bacon, Mechanical Metallurgy. 1988: McGraw-Hill.

102. Takamura, S., et al., Formation of Nanostructured Tungsten with Arborescent Shape due to Helium Plasma Irradiation. Plasma and Fusion Research, 2006. 1: p. 051-051.

103. Zhang, N., et al., Trapping of helium atom by vacancy in tungsten: a density functional theory study. The European Physical Journal B, 2017. 90(5): p. 101.

104. Yang, Y., et al., Roles of vacancy/interstitial diffusion and segregation in the microchemistry at grain boundaries of irradiated Fe-Cr-Ni alloys. Journal of Nuclear Materials, 2016. 473: p. 35-53.

105. Yang, L. and B.D. Wirth, Energetics of hydrogen and helium-vacancy complexes in bulk and near surfaces of tungsten: First-principles study. Journal of Applied Physics, 2018. 123(21): p. 215104.

106. Wu, X., et al., First principles study of helium trapping by solute elements in tungsten. Journal of Nuclear Materials, 2014. 455(1): p. 151-156.

107. Nakashima, K., R.E. Stoller, and H. Xu, Recombination radius of a Frenkel pair and capture radius of a self-interstitial atom by vacancy clusters in bcc Fe. Journal of Physics: Condensed Matter, 2015. 27(33): p. 335401. 
108. Van Brutzel, L., A. Chartier, and J.P. Crocombette, Basic mechanisms of Frenkel pair recombinations in $\$\{\mid$ text $\{\cup 0\}\}\{\{2\} S$ fluorite structure calculated by molecular dynamics simulations. Physical Review B, 2008. 78(2): p. 024111.

109. van Gog, H. and M.A. van Huis, Structural and Electronic Properties of Frenkel and Schottky Defects at the MgO\{100\} Surface: Spin Polarization, Mid-Band Gap States, and Charge Trapping at Vacancy Sites. The Journal of Physical Chemistry C, 2019. 123(23): p. 14408-14420.

110. Dubinko, V.I., Radiation damage and recovery of crystals:Frenkel vs. Schottky defect production. arXiv: Materials Science, 2014.

111. Frenkel, J., Über die Wärmebewegung in festen und flüssigen Körpern. Zeitschrift für Physik, 1926. 35(8): p. 652-669.

112. Miyamoto, M., et al., In situtransmission electron microscope observation of the formation of fuzzy structures on tungsten. Physica Scripta, 2014. T159: p. 014028.

113. Hwangbo, D., et al., Growth process of nano-tendril bundles with sputtered tungsten. Nuclear Materials and Energy, 2019. 18: p. 250-257.

114. Wright, G.M., et al., Comparison of tungsten nano-tendrils grown in Alcator C-Mod and linear plasma devices. Journal of Nuclear Materials, 2013. 438: p. S84-S89.

115. Wright, G.M., et al., Tungsten nano-tendril growth in the Alcator C-Mod divertor. Nuclear Fusion, 2012. 52(4): p. 042003.

116. Kajita, S., et al., Enhanced growth of large-scale nanostructures with metallic ion precipitation in helium plasmas. Scientific Reports, 2018. 8(1): p. 56.

117. El Atwani, O., et al., In-Situ Helium Implantation and TEM Investigation of Radiation Tolerance to Helium Bubble Damage in Equiaxed Nanocrystalline Tungsten and Ultrafine Tungsten-TiC Alloy. Materials, 2020. 13(3).

118. Kong, X.-S., et al., The role of impurity oxygen in hydrogen bubble nucleation in tungsten. Journal of Nuclear Materials, 2013. 433(1): p. 357-363.

119. López-Ruiz, P., et al., Powder metallurgical processing of self-passivating tungsten alloys for fusion first wall application. Journal of Nuclear Materials, 2013. 442(1, Supplement 1): p. S219-S224.

120. Yamagiwa, M., et al., Helium bubble formation on tungsten in dependence of fabrication method. Journal of Nuclear Materials, 2011. 417(1): p. 499-503.

121. Bakaev, A., et al., Ab initio study of interaction of helium with edge and screw dislocations in tungsten. Nuclear Instruments and Methods in Physics Research Section B: Beam Interactions with Materials and Atoms, 2017. 393: p. 150-154.

122. Abdou, M., et al., Blanket/first wall challenges and required R\&D on the pathway to DEMO. Fusion Engineering and Design, 2015. 100: p. 2-43.

123. Beckers, M., et al., Investigations of the first-wall erosion of DEMO with the CELLSOR code. Nuclear Materials and Energy, 2017. 12: p. 1163-1170.

124. Clinard Jr, F.W., First wall materials problems in fusion reactors. 1974, Los Alamos Scientific Lab., N. Mex.(USA).

125. Huang, Y., M.S. Tillack, and N.M. Ghoniem, Tungsten monoblock concepts for the Fusion Nuclear Science Facility (FNSF) first wall and divertor. Fusion Engineering and Design, 2018. 135: p. 346355.

126. Linsmeier, C., et al. Advanced first wall and heat sink materials. in 1st IAEA DEMO Programme Workshop. 2012.

127. Litnovsky, A., et al., Smart tungsten alloys as a material for the first wall of a future fusion power plant. Nuclear Fusion, 2017. 57(6): p. 066020.

128. Litnovsky, A., et al., Smart alloys for a future fusion power plant: First studies under stationary plasma load and in accidental conditions. Nuclear Materials and Energy, 2017. 12: p. 1363-1367. 
129. Matthews, G.F., Plasma operation with an all metal first-wall: Comparison of an ITER-like wall with a carbon wall in JET. Journal of Nuclear Materials, 2013. 438: p. S2-S10.

130. Orient, G., P. Gierszewski, and J. Garner, Elastic-plastic analysis of slender first wall structures. Fusion Technology, 1985. 8(1P2A): p. 586-591.

131. Pestchanyi, S., Simulation of Heat Flux to the DEMO First Wall Due to Filamentary Transport in the Far SOL. IEEE Transactions on Plasma Science, 2018. 46(5): p. 1393-1397.

132. Tunç, G., H.M. Şahin, and S. Şahin, Evaluation of the radiation damage parameters of ODS steel alloys in the first wall of deuterium-tritium fusion-fission (hybrid) reactors. International Journal of Energy Research, 2018. 42(1): p. 198-206.

133. Wang, S., et al., Thermal-hydraulic analysis of the First Wall of a CO2 cooled pebble bed breeding blanket for the EU-DEMO. Fusion Engineering and Design, 2019. 138: p. 379-394.

134. Abdou, M.A., et al., Results of an International Study on a High-Volume Plasma-Based Neutron Source for Fusion Blanket Development. Fusion Technology, 1996. 29(1): p. 1-57.

135. Abdou, M.A., M. Tillack, and A.R. Raffray, Thermal, fluid flow, and tritium release problems in fusion blankets. Fusion Technology, 1990. 18(2): p. 165-200.

136. Giancarli, L., et al., Breeding Blanket Modules testing in ITER: An international program on the way to DEMO. Fusion Engineering and Design, 2006. 81(1): p. 393-405.

137. Gierszewski, P.J., M.A. Abdou, and R. Puigh, Fission Reactor Experiments for Solid Breeder Blankets. Fusion Technology, 1986. 10(3P2B): p. 1097-1101.

138. Golfier, H., et al., Progress on the TAURO blanket system. Fusion Engineering and Design, 2002. 61-62: p. 461-470.

139. Malang, S. and D.L. Smith, Modeling of liquid-metal corrosion/deposition in a fusion reactor blanket. 1984: United States.

140. Malang, S., et al., Development of the Lead Lithium (DCLL) Blanket Concept. Fusion Science and Technology, 2011. 60(1): p. 249-256.

141. Smith, D.L., et al., Overview of the Blanket Comparison and Selection Study. Fusion Technology, 1985. 8(1P1): p. 10-44.

142. Smith, D.L. and G. Morgan, Blanket comparison and selection study, in ANL/FPP-84-1. 1984, Argonne National Laboratory Argonne, IL.

143. Tillack, M.S., D.K. Sze, and M.A. Abdou, Required Momentum, Heat, and Mass Transport Experiments for Liquid Metal Blankets. Fusion Technology, 1986. 10(3P2B): p. 1088-1096.

144. Albanese, R., DTT: a divertor tokamak test facility for the study of the power exhaust issues in view of DEMO. Nuclear Fusion, 2016. 57(1): p. 016010.

145. Cao, C., et al., Predictive modeling of HL-2M divertor operation by SOLPS-ITER. Fusion Engineering and Design, 2018. 136: p. 822-827.

146. Hirai, T., et al., Status of technology R\&D for the ITER tungsten divertor monoblock. Journal of Nuclear Materials, 2015. 463: p. 1248-1251.

147. Hirai, T., et al., Use of tungsten material for the ITER divertor. Nuclear Materials and Energy, 2016. 9: p. 616-622.

148. Ihli, T., et al., Integration of an advanced He-cooled divertor in a DEMO-relevant tokamak geometry. Fusion Engineering and Design, 2006. 81(1): p. 121-126.

149. Matthews, G.F., Material migration in divertor tokamaks. Journal of Nuclear Materials, 2005. 337339: p. 1-9.

150. Wurster, S., et al., Recent progress in R\&D on tungsten alloys for divertor structural and plasma facing materials. Journal of Nuclear Materials, 2013. 442(1, Supplement 1): p. S181-S189.

151. Aubert, P., et al., Review of candidate welding processes of RAFM steels for ITER test blanket modules and DEMO. Journal of Nuclear Materials, 2011. 417(1): p. 43-50. 
152. Baylor, L.R., et al., Pellet fuelling and control of burning plasmas in ITAB - Pellet injection from the inner wall is planned for use in ITER as the primary core fuelling system since gas fuelling is expected to be highly inefficient in burning plasmas. Tests of the inner wall guide tube have shown that $5 \mathrm{~mm}$ pellets with up to $300 \mathrm{~m} \mathrm{~s}-1$ speeds can survive intact and provide the necessary core fuelling rate. Modelling and extrapolation of the inner wall pellet injection experiments from present day's smaller tokamaks leads to the prediction that this method will provide efficient core fuelling beyond the pedestal region. Using pellets for triggering of frequent small edge localized modes is an attractive additional benefit that the pellet injection system can provide. A description of the ITER pellet injection system's capabilities for fuelling and ELM triggering is presented and performance expectations and fusion power control aspects are discussed. ER. Nuclear Fusion, 2007. 47(5): p. 443-448.

153. Bolt, H., et al., Plasma facing and high heat flux materials - needs for ITER and beyond. Journal of Nuclear Materials, 2002. 307-311: p. 43-52.

154. Busby, J.T., et al., Development of high performance cast stainless steels for ITER shield module applications. Journal of Nuclear Materials, 2011. 417(1): p. 866-869.

155. Davis, J.W., et al., Assessment of tungsten for use in the ITER plasma facing components1\#AC3013 with Sandia National Laboratories.1. Journal of Nuclear Materials, 1998. 258-263: p. 308312.

156. Giancarli, L.M., et al., Overview of the ITER TBM Program. Fusion Engineering and Design, 2012. 87(5): p. 395-402.

157. Hirai, T., et al., Cracking failure study of ITER-reference tungsten grade under single pulse thermal shock loads at elevated temperatures. Journal of Nuclear Materials, 2009. 390-391: p. 751-754.

158. Liu, L., et al., High-flux He+ irradiation effects on surface damages of tungsten under ITER relevant conditions. Journal of Nuclear Materials, 2016. 471: p. 1-7.

159. Roth, J., et al., Recent analysis of key plasma wall interactions issues for ITER. Journal of Nuclear Materials, 2009. 390-391: p. 1-9.

160. Song, I., et al. The fast discharge system of ITER superconducting magnets. in 2011 International Conference on Electrical Machines and Systems. 2011. IEEE.

161. Taylor, N., et al., Preliminary safety analysis of ITER. Fusion Science and Technology, 2009. 56(2): p. 573-580.

162. Taylor, N., et al., Updated safety analysis of ITER. Fusion Engineering and Design, 2011. 86(6): p. 619-622.

163. Taylor, N. and P. Cortes, Lessons learnt from ITER safety \& licensing for DEMO and future nuclear fusion facilities. Fusion Engineering and Design, 2014. 89(9): p. 1995-2000.

164. Testa, D., et al., The magnetic diagnostic set for ITER. IEEE Transaction on Plasma Science, 2010. 38(ARTICLE): p. 284-294.

165. van Houtte, D., K. Okayama, and F. Sagot, RAMI Approach for ITER. Fusion Engineering and Design, 2010. 85(7): p. 1220-1224.

166. Garofalo, A.M., et al., A Fusion Nuclear Science Facility for a fast-track path to DEMO. Fusion Engineering and Design, 2014. 89(7): p. 876-881.

167. Hermsmeyer, S., et al., Reactor integration of the helium cooled pebble bed blanket for DEMO. Fusion Engineering and Design, 2005. 75-79: p. 779-783.

168. Hermsmeyer, S., et al. Revision of the EU helium cooled pebble bed blanket for DEMO. in 20th IEEE/NPSS Symposium onFusion Engineering, 2003. 2003.

169. Kuteev, B.V., et al., Development of DEMO-FNS tokamak for fusion and hybrid technologies. Nuclear Fusion, 2015. 55(7): p. 073035.

170. Maisonnier, D., et al., DEMO and fusion power plant conceptual studies in Europe. Fusion Engineering and Design, 2006. 81(8): p. 1123-1130. 
171. Malang, S., et al., European Blanket Development for a DEMO Reactor. Fusion Technology, 1994. 26(3P2): p. 1069-1078.

172. Tanabe, T., Tritium fuel cycle in ITER and DEMO: Issues in handling large amount of fuel. Journal of Nuclear Materials, 2013. 438: p. S19-S26.

173. Wenninger, R., et al., The DEMO wall load challenge. Nuclear Fusion, 2017. 57(4): p. 046002.

174. Dieter, G.E., Mechanical Metallurgy. 1976: McGraw-Hill.

175. Callister, W.D. and D.G. Rethwisch, Fundamentals of Materials Science and Engineering: An Integrated Approach. 2012: Wiley.

176. Smith, W.F. and J. Hashemi, Foundations of Materials Science and Engineering. 2004: McGrawHill.

177. Diffusion Kinetics in Solids, in Phase Transformations in Materials. p. 171-238.

178. Abbaschian, R. and R.E. Reed-Hill, Physical Metallurgy Principles. 2008: Cengage Learning.

179. Chen, L., et al., Stability and diffusion properties of self-interstitial atoms in tungsten: a firstprinciples investigation. Science China Physics, Mechanics and Astronomy, 2012. 55(4): p. 614618.

180. Mehrer, H., Diffusion in Solids: Fundamentals, Methods, Materials, Diffusion-Controlled Processes. 2007: Springer Berlin Heidelberg.

181. Kusunoki, K., Molecular-Dynamics Study of Self-Interstitial Diffusion in bcc-Iron. MATERIALS TRANSACTIONS, 2006. 47(8): p. 1906-1909.

182. Meyers, M.A. and K.K. Chawla, Mechanical Behavior of Materials. 2008: Cambridge University Press.

183. Hosford, W.F., Mechanical Behavior of Materials. 2010: Cambridge University Press.

184. Xie, H., et al., Trapping of hydrogen and helium at an $\{110\}<111>$ edge dislocation in tungsten. Journal of Nuclear Materials, 2017. 484: p. 270-275.

185. Luo, G.N., et al., Overview of decade-long development of plasma-facing components at ASIPP. Nuclear Fusion, 2017. 57(6): p. 065001.

186. Luo, G.N., et al., Overview of plasma-facing materials and components for EAST. Physica Scripta, 2007. T128: p. 1-5.

187. Beck, M., M. Ellner, and E.J. Mittemeijer, The formation of interstitial solid solutions based on solvents showing the fcc structure: elastic versus chemical interaction. Acta Materialia, 2001. 49(6): p. 985-993.

188. Hägg, G., Solid Solutions with a Varying Number of Atoms in the Unit Cell. Zeitschrift für Kristallographie - Crystalline Materials, 1935. 91(1): p. 114.

189. Zener, C., Theory of Growth of Spherical Precipitates from Solid Solution. Journal of Applied Physics, 1949. 20(10): p. 950-953.

190. Qin, J., et al., The self-diffusion coefficients of liquid binary M-Si (M=Al, Fe, Mg and Au) alloy systems by first principles molecular dynamics simulation. AIP Advances, 2019. 9(3): p. 035328.

191. Zhang, B., Calculation of self-diffusion coefficients in iron. AIP Advances, 2014. 4(1): p. 017128.

192. Varotsos, P. and K. Alexopoulos, Calculation of diffusion coefficients at any temperature and pressure from a single measurement. I. Self diffusion. Physical Review B, 1980. 22(6): p. 31303134.

193. Hirai, T. and G. Pintsuk, Thermo-mechanical calculations on operation temperature limits of tungsten as plasma facing material. Fusion Engineering and Design, 2007. 82(4): p. 389-393.

194. El-Guebaly, L., et al., W-Based Alloys for Advanced Divertor Designs: Options and Environmental Impact of State-of-the-Art Alloys. Fusion Sci. Technol., 2011. 60: p. 185-189.

195. Bolt, H., et al., Materials for the plasma-facing components of fusion reactors. Journal of Nuclear Materials, 2004. 329-333: p. 66-73.

196. Introduction to physical metallurgy. 1997: McGraw-Hill Education (India) Pvt Limited. 
197. Rafique, M.M.A., Modeling and Simulation of Heat Transfer Phenomena. 2015.

198. Rafique, M.M.A. and J. Iqbal, Modeling and simulation of heat transfer phenomena during investment casting. International Journal of Heat and Mass Transfer, 2009. 52(7-8): p. 2132-2139. 